\title{
Scientific Knowledge and Technology Transfer Policy in the EU
}

\author{
Auste Kiskiene, Kazimieras Simonavicius University
}

\begin{abstract}
The article focuses on identifying possibilities to facilitate scientific knowledge and technology transfer and commercialization by means of public policy. Theoretical rationale for technology transfer public policy is analysed, specifically-market failure, system failure and authors' suggested cultural failure approaches are discussed. Based on the theoretical approaches, the EU public policy and the example of Lithuanian public policy in the field of technology transfer is analysed. Recommendations for adopting ecosystem approach towards fostering technology transfer are presented.
\end{abstract}

Keywords - Innovation policy, knowledge and technology transfer, knowledge and innovation based economy, technology transfer policy.

\section{INTRODUCTION}

Knowledge and technology transfer is crucial for sustainable development of the current economy and society, which are defined as knowledge intensive and innovation based. Yet the success of knowledge and technology transfer depends to a great degree on the existing support mechanisms and favourable environment. It is argued, that the transfer of knowledge and technologies created in scientific institutions (scientific knowledge) to business and society is prone to market failure due to specific financial, legal and social (communication) problems, which impede natural meeting of supply and demand. Such situation requires systematic approach, including more or less active participation of government in the form of fostering, encouraging and regulating policies. The principal question of scientific knowledge and technology transfer is not whether it shall be managed actively by means of public policy, but how it should be done.

This article analyses public policy and focuses on identifying possibilities to facilitate scientific knowledge and technology transfer from scientific institutions to business by means of public policy. The first part of the article briefly overviews the definition and the main characteristics of the knowledge and technology transfer process. Theoretical rationale for government intervention in knowledge and technology transfer issues is analysed, specifically - market failure, system failure and the author's suggested cultural failure approaches are discussed. The second part analyses the EU mechanisms and recommendations in this field. Case analysis of Lithuanian public policy, which is aimed at fostering scientific knowledge and technology transfer, is provided. Conclusions and recommendations are presented in the last part of the article.
The research is based on qualitative methods: theoretical analysis; systematic content analysis and comparative analysis. Lithuanian and the EU public policy documents are analysed and evaluated in the framework of market failure, system failure and cultural failure approaches, which are presented in the second part of the article.

\section{KNOWLEDGE AND TECHNOLOGY TRANSFER PROCESS AND ITS CHARACTERISTICS}

Knowledge and technology transfer is best defined as a communication process, which involves the creator of an idea and the implementer of that idea. Usually this process involves interaction between scientists and science institutions universities, research institutes, etc. - and entrepreneurs and business ventures. The aim of such interaction is to apply and commercialize the results of scientific research. Knowledge and technology transfer is a process, which connects science and business with the end goal to produce innovations for the benefit of society, economy and overall development [1].

This process is usually referred to as technology transfer, however, knowledge, especially tacit knowledge, is integral to every scientific idea or research results, thus it is more accurate and scientifically correct to use knowledge and technology transfer concept. Moreover, different kind of knowledge - not only technological, can be transferred, applied and commercialized. In current knowledge society such business fields as creative industries, social innovations, culture, etc., are gaining more and more importance.

All scientists, working in the field, agree that knowledge and technology transfer process is complex, difficult, and has many characteristics, which can impede the achievement of the end goal, i.e., commercialization. Based on the analysis of scientific literature [2]- [6], there can be distinguished four main characteristics of knowledge and technology transfer process.

- There is a variety of objects, which can be transferred: competences, best practices and other tacit knowledge, theoretical calculations, schemes, measurement results, methods, as well as prototypes, working mechanisms or other material objects. Such variety makes it difficult to record, analyze and assess the scope and quality of knowledge and technology transfer processes.

- Technology transfer usually connects two different societal groups - scientists and businesspersons. Both groups have their own and different work ethics, goals, expectations and processes, which create a gap between science and business in terms of communication and cooperation. 
- Non-formal communication and explicit networks are crucial prerequisites for the successful knowledge and technology transfer process. Without non-formal ties, it is difficult for the actors involved in the transfer process to share tacit knowledge, assess the commercialization potential of scientific ideas and research results and develop viable business plans.

- Uncertainty and spillover effect. Private investors cannot be certain whether the research or even prototype, in the development of which they invested, will result in desirable commercial outcomes. Even if knowledge or technology development brought desirable results, there is possibility that eventually competitors will be able to use them after initial investments made breakthrough in certain technological field possible.

These characteristics determine that knowledge and technology transfer from science to business is a complex process, which requires facilitation, favourable conditions and support. Currently almost no European country has achieved the desirable level of innovativeness (at least in comparison with such countries as the United States or Japan) [7]. All main statistical data and research show that science commercialization rarely works by the classical free market principles. Thereof classical theoretical approach - such as Triple-Helix theory or National Innovation System theory argues, that knowledge and technology transfer is successful only when government interacts with science and business and forms adequate and favourable environment for science commercialization [8], [9].

It is widely acknowledged that knowledge and technology transfer and innovations are the key drivers in the long-term economic and societal development. Innovation has been a hot topic in European and other countries for more than 30 years and this trend is reflected in strategic and political documents as well as in scientific research. Interaction between science, business and government has been analyzed and it is suggested that general technological development is dependent on complex and dynamic interaction between these three sectors.

Based on such assumptions new expectations are formed regarding the performance of scientific institutions universities, research institutes, laboratories, etc. Etzkowitz and Webster named this trend "academic revolution", leading to the formation of "entrepreneurial universities", which besides their two main functions - education and research now have to perform the third function - commercialization of the research results [10].

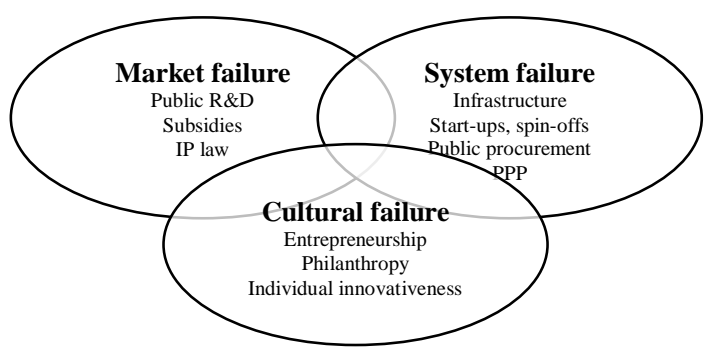

Fig. 1. The three failures of the knowledge and technology transfer process.
Governments from around the world make a successful economic development their top priority. This goal requires focusing more and more on the policy that can create favourable conditions and lead to innovative and high-tech based economy. Governments search for the most effective policy means and management models, which can improve knowledge and technology transfer and commercialization indicators. Theoretical rationale for government intervention in knowledge and technology transfer processes is found in two main theories-neo-classical economic theory and systems theory. Neo-classical economic theory provides background for the market failure approach and systems theory - for system failure approach. In addition to these two main approaches the third one - cultural failure approach can be distinguished (see Fig. 1).

Market failure rationale is based on Arrow-Nelson argument about market failure [11]-[13]. The approach defines knowledge and technology as public goods and analyses government intervention in research and development $(\mathrm{R} \& \mathrm{D})$ management. The main argument for the government public policy in the field of knowledge and technology transfer is based on the assumption that market forces are insufficient to ensure the desirable or optimal supply and demand of knowledge and technology. In ideal conditions, competition should ensure achieving Pareto efficiency, however knowledge and technology market is strongly influenced by the characteristics of knowledge and technology transfer process, which impede the market forces. The characteristics, which were analysed in the first part of the article, create the environment, where costs of knowledge and technology transfer are too high for the participants of this process, private investors cannot be certain about the results of scientific research (the uncertainty argument), information asymmetry prevents potential cooperation between science and business, imperfect capital market provides little funding possibilities for the development of scientific ideas, etc. Social benefits of the development and commercialisation of scientific knowledge and technology are higher than the potential commercial gain from the investment in knowledge and technology. Thus, society has higher needs for the innovations than private companies can satisfy with their willingness to accept the risk of investments in science and technology. Government can intervene with the aim to correct this mismatch and compensate for the market failure. The main public policy means, which are based on market failure rationale, are: 1) public $R \& D$ funding; 2) subsidies for $R \& D$; 3) intellectual property regime; and 4) competition policy instruments. These public policy means are focused on the relocation of resources and supply side problems. The logic of market failure approach suggests that the increasing investment in R\&D and favourable legal environment for the inventors and innovators can stimulate knowledge creation. Thereof increasing supply of knowledge and technologies will result in more practical applications and commercialization, i.e., products, services, business ventures, etc.

The system failure rationale is based on systems theory and particularly on National Innovation System approach [2], 
[11] - [12], [14] which argues that innovation environment in the state is dependent on the complex relationships among the main actors-government, science institutions, private ventures, innovation support agencies, private investors, innovators, scientists, entrepreneurs, etc. The main argument for the government intervention is based on the assumption that knowledge and technology transfer process is not working because of the structural, institutional, regulation, and communication problems and shortcomings. This approach analyses interaction of the main actors of knowledge and technology transfer process and the impact of such interaction on successful networking, mutual learning, new knowledge creation and commercialization. The characteristics of knowledge and technology transfer process can create such environment where communication between science and business is limited, innovation support infrastructure is not working or is rudimental, innovation system does not evolve and adapt to the changing global and national conditions. Therefore, actors and stakeholders do not understand the importance of cooperation and undervalue the benefits of knowledge commercialization. The research based on the system failure approach focuses on the demand side problems of knowledge and technology transfer process. The government public policy means are designed for the improvement of innovation support and facilitation infrastructure and include the development of science and technology parks, technology transfer offices/centres, financial support for the creation and development of innovative spinoffs, development of pre-seed, seed and risk capital investment infrastructure, development of pre-incubation and incubation services, creation and strengthening of innovation support organizations, programs for promoting cooperation between science and business, favourable legal and political conditions for knowledge and technology transfer, etc. The system failure rationale directs public policy towards more holistic and systemic planning of support mechanisms, instruments and infrastructure, which should create favourable environment and enough incentive for scientists and entrepreneurs to engage in knowledge and technology transfer and commercialization.

The third way to look at the knowledge and technology transfer process comes from the cultural point of view and can be called a cultural failure. Lack of general culture, which supports entrepreneurship, innovativeness, community, openness and trust, can greatly impede the chances of successful knowledge and technology transfer. Historically science, especially in Anglo-Saxon countries, was funded through philanthropy and community [15]. Even nowadays community involvement in science institutions through alumni, philanthropy, foundations, councils and other means can significantly promote technology transfer activities. This broader involvement solves such problems as lack of trust and information asymmetry and narrows the gap between science and business communities/society. Philanthropy can significantly contribute to the funding of scientific research, especially to fundamental or early stage research, which usually lacks sufficient funding from business because of high risk and uncertainty of the results. However, European countries lack the culture of philanthropy, which can be attributed to the domination of the welfare state model, where the state is responsible for the provision of major social goods, including science and technological development [16]. Entrepreneurial and innovative culture also is a prerequisite for the effective and successful technology transfer process. Schumpeter defined an entrepreneur as a revolutionary innovator who creates the most significant changes in economy [17]. Entrepreneurs are the ones who notice valuable ideas and mobilize resources to implement them. However, entrepreneurship is not a generally present feature of the modern Western society. Governments through public policy means can invest resources in the development and promotion of favourable culture for the technology transfer processes. Public information campaigns, tax exemptions, favourable legal environment, public-private partnership, and other facilitating measures can effectively promote philanthropy and entrepreneurship [18]. Ex post prizes for innovativeness and creativity, competitions for new technologies, incentives for venture capitalists, who invest in innovative technologies, and for private inventors, can inform public about the value and importance of innovations to the economic development. Encouragement and support for social capital development projects and other so-called soft initiatives can eventually contribute to the desired change in society [19]. The suggested cultural failure approach can show public policy planners and implementers that cultural background can be the source of major problems in technology transfer field, and that general horizontal and soft measures are very important for promoting technology transfer, innovativeness and economic development.

Based on the analysis of theoretical rationales for the government involvement in technology transfer regulation and management, it can be concluded that governments have a wide range of public policy means to influence, support and promote technology transfer processes. The market failure, system failure and cultural failure approaches constitute a useful tool for the classification and analysis of state public policy in the field of scientific knowledge and technology transfer.

\section{THE EU KNOWLEDGE AND TECHNOLOGY TRANSFER POLICY}

\section{A. The EU Approach to the Scientific Knowledge and Technology Transfer}

The EU knowledge and technology transfer policy is defined through a wide variety of strategic documents. The EU approach is based on the recognition and acknowledgment of the importance of the knowledge and technology transfer policy as well as of the major common problems in the field of scientific knowledge and technology transfer.

The EU public policy widely acknowledges the importance innovations have in the context of the long-term socioeconomic development. Both earlier Lisbon strategy and current growth strategy "Europe 2020" emphasise smart 


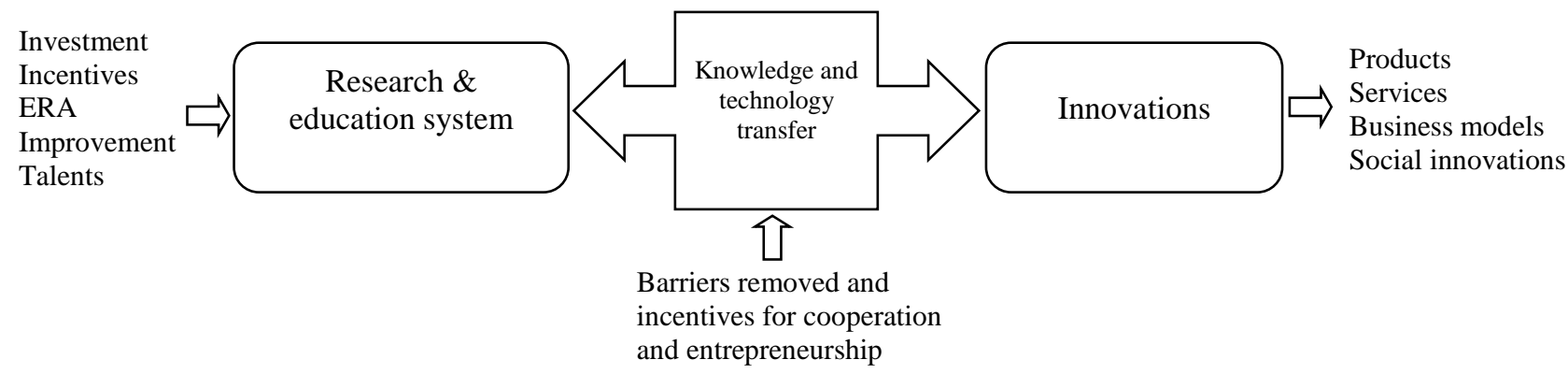

Fig. 2. The EU approach to the role of scientific knowledge and technology transfer process.

knowledge economy [20]. The field of innovation is among the five main objectives of "Europe 2020", supported by the flagship initiative "Innovation Union" [21]. It can be argued that the knowledge and technology transfer process is at the heart of the EU understanding of innovation development. The EU approach to the knowledge and technology transfer process is summarized in Fig. 2.

Fig. 2 shows that the EU emphasises the importance of strengthening research and development as well as education system in the EU countries as a prerequisite to the knowledge and technology transfer and innovation development. The competitiveness of research is based on adequate investments and incentives, improvement of infrastructure, international cooperation through European networks (such as ERA European Research Area) and recruitment of the most talented researchers. Knowledge and technology transfer is the communication medium which connects science and innovation and fosters the creation and development of new products, services and social innovations, which can make a difference in the society. Knowledge and technology transfer is understood as a two way process, which transforms research into commercial or social value and also brings feedback about the market needs and demands to the scientific institutions. The flagship initiative "Innovation Union" of the growth strategy "Europe 2020" emphasises that Europe's future economic growth and jobs will increasingly have to rely on the innovation in products, services and business models. The importance of social innovations is also increasingly emphasised in the EU's strategic documents, and it is argued that creativity, innovativeness and entrepreneurship are driving forces in all spheres of social life as well as in business and governance fields.

Despite formal recognition of the significant role of the scientific knowledge and technology transfer to the economic development there is a number of problems which are common throughout the entire EU. These problems impede the effectiveness of knowledge and technology transfer, which result in non satisfactory levels of innovativeness and economic growth. The common EU problems of knowledge and technology transfer are identified in the main studies and strategic documents [22] and can be classified into three groups:

- scientific knowledge and technology demand and supply problems, i.e., low quality/low importance research, lack of applied research, low level of technology absorption in the business sector, low overall innovativeness of businesses;

- unsupportive infrastructure for effective technology transfer, i.e., inadequate incentives for the potential actors to get involved in knowledge and technology transfer process;

- low level of cooperation between science and business.

The EU recommendations and solutions can be grouped according to the main problems they are addressing and to the theoretical justification of the three failures approach, which is summarized in Fig. 3. Recommendations, which are typical for the market failure approach and usually address

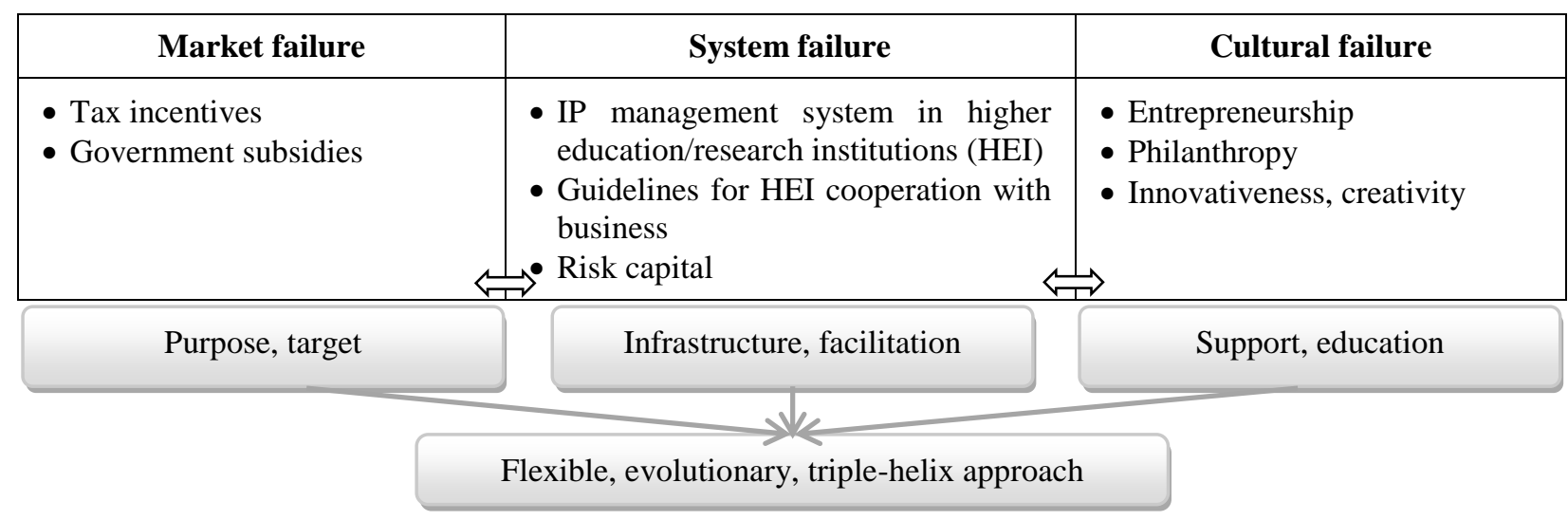

Fig. 3. The EU knowledge and technology policy recommendations, systematized according to the three failures approach. 
demand and supply problems, are tax incentives for the companies, which are investing in research and government subsidies allocated to the fundamental and applied research. The EU recommendations highlight the need to increase private and governmental investments in research and set higher goals than the EU average goals for the member countries to achieve. The system failure recommendations and solutions tackle infrastructure problems which impede knowledge and technology transfer from higher education/research institutions to business. Among the recommendations of this type particularly well elaborated are the guidelines for the higher education/research institutions regarding their intellectual property management systems and cooperation with business [23]. The development of the risk capital infrastructure also is discussed in several policy and recommendation papers [24]. Issues of knowledge and technology transfer problems which are basically cultural by their nature, are addressed through the promotion of entrepreneurship, innovativeness and creativity. Philanthropy is also seen as a means, which is applied in other countries (especially in the USA) for bridging scientific and business communities and ensuring funding for the breakthrough research, but is not adequately exploited in the EU [25].

As it is seen in Fig. 3, all three types of recommendations and solutions focus at different, though interconnected knowledge and technology transfer problems and aim to improve situation respectively. Recommendations, based on the market failure approach, highlight the need for a welldefined, clear purpose and target of all governmental investments and other subsidies/financial incentives, which can enhance the productivity and quality of research and development (R\&D). The purpose of such subsidies has to be directly connected with the applied research and target sectors, which have the most potential for the R\&D commercialization. Recommendations, based on the system failure, aim to create and/or improve infrastructure, which is crucial for the facilitation of the scientific knowledge and technology transfer. Infrastructure is not only "hard" or physical, but in many cases - "soft", i.e., political and regulatory framework, functioning and coherent national innovation system, effective knowledge and technology transfer policy within higher education/research institutions, etc. Recommendations, based on the cultural failure approach, target the need to educate actors, directly involved in the knowledge and technology transfer process, as well as wider public. Education is very important for understanding knowledge and technology transfer and commercialisation and for developing entrepreneurial culture, especially among researchers and students. The environment, which is favourable and supportive for entrepreneurial pursuits of researchers, stimulates scientific knowledge and technology transfer and innovation.

The analysis of the strategic documents shows that the EU supports flexible and evolutionary approach towards knowledge and technology transfer policy. The EU recommendations to the member states emphasise the need to create favourable environment for the $R \& D$ commercialization within scientific institutions and on national level in the form of support to the entrepreneurial initiatives, to the cooperation between government, business and scientific institutions, and to the competitive and purposeful R\&D funding schemes.

\section{B. Analysis of Scientific Knowledge and Technology Transfer Public Policy in Lithuania}

Case analysis of Lithuanian scientific knowledge and technology transfer public policy shows disconnect between the strategic goals and the practical application. Innovation and science-business cooperation is emphasized on the strategic political level, which is highly influenced by the EU recommendations. The development of knowledge society and knowledge based economy are among the priorities of the main strategic planning documents (State Long Term Development Strategy, Lithuanian Economic Development Long Term Strategy until 2015, Government Actions Program, Lithuanian Innovation Strategy 2010 - 2020, High Technology Development Program 2011 - 2013 and others). Importance of applied research, effective innovation system, private investment in the $\mathrm{R} \& \mathrm{D}$ and the development of hightech business sectors are highlighted.

Public policy, which addresses the challenges of scientific knowledge and technology transfer process in Lithuania, is analysed according to the three failures approach (Table I). The main public policy means, which aim to solve market failures, are: 1) public R\&D financing; 2) government subsidies; 3) tax incentives. The analysis of Lithuanian situation shows that during the last 5 years more emphasis has been put on promoting competitive R\&D financing approach. This is a positive development, since government subsidies and grants are allocated based on the competition of the submitted R\&D commercialization projects. However, main share of the funding available to the R\&D projects comes through the EU Structural Funds. This increases overall available financing, but many companies and scientific

TABLE I

STRENGTHS AND WEAKNESSES OF SCIENTIFIC KNOWLEDGE AND TECHNOLOGY TRANSFER POLICY IN LiTHUANIA

\begin{tabular}{|c|c|c|c|c|c|}
\hline \multicolumn{2}{|c|}{ Market failure } & \multicolumn{2}{|c|}{ System failure } & \multicolumn{2}{|c|}{ Cultural failure } \\
\hline Strengths & Weaknesses & Strengths & Weaknesses & Strengths & Weaknesses \\
\hline $\begin{array}{l}\text { Competitive financing } \\
\text { approach }\end{array}$ & $\begin{array}{l}\text { The EU Structural } \\
\text { Funds } \\
\text { Institution based } \\
\text { financing } \\
\text { Lack of financing }\end{array}$ & $\begin{array}{l}\text { Science, study and } \\
\text { business centres } \\
\text { (valleys) } \\
\text { Innovation support } \\
\text { services } \\
\text { Legal framework }\end{array}$ & $\begin{array}{l}\text { Consultations and } \\
\text { trainings } \\
\text { Science push approach } \\
\text { Quantity vs. quality } \\
\text { Hard infrastructure }\end{array}$ & $\begin{array}{l}\text { Entrepreneurship } \\
\text { education (youth, } \\
\text { students, academic) } \\
\text { Science and } \\
\text { technology promotion }\end{array}$ & $\begin{array}{l}\text { Formal approach } \\
\text { Rigid conditions }\end{array}$ \\
\hline
\end{tabular}


institutions tend to focus only on short term goals of attracting the EU funding instead of focusing on market needs for technology commercialisation. Institution based financing is another weakness of Lithuanian public policy in the field. Majority of the public $R \& D$ funding is allocated to the institutions. This tendency gives less flexibility for the academic and business pursuits of the scientists and for their cooperation with business sector. The final major weakness of the scientific knowledge and technology transfer policy in Lithuania according to the market failure approach is lack of available public and private financing for $R \& D$ [26]. This is a common problem throughout the EU, which results in low quality of R\&D outputs, low supply of scientific knowledge and technology for commercialisation and low interest from the business sector to cooperate with the scientific institutions in technology transfer and commercialisation.

System failure approach encourages governments to adopt systemic public policy and focus on the promotion of favourable environment and viable communication links necessary for the scientific knowledge and technology transfer and commercialisation. Lithuanian public policy means, which aim to solve technology transfer problems through the systemic approach, are: 1) development of innovation support services; 2) support for the start-ups/spin-offs; 3) promotion of the risk capital infrastructure; 4) support for science-business cooperation. Based on this approach a few strengths of the public policy application can be identified: the focus on the development of the integrated science, study and business centres (valleys); the focus on the public innovation support services; and the improvement of the legal framework necessary for the facilitation of the scientific knowledge and technology transfer and commercialization. There were five integrated science, study and business centres (valleys) created in Lithuania during the last decade [27]. The valleys aim at bridging science and business through the development of open access R\&D infrastructure, science and technology parks and innovation support services for scientists and business. The available public innovation support services mainly focus on providing specialized consultation and incubation services (including subsidized office space) for the knowledge and technology based start-ups/spin-offs. There are examples of the public private partnership in the development of risk capital infrastructure for the start-ups/spin-offs (for example, Business Angels Fund I, founded by the European Investment Fund and co-investing together with private "business angels" [28]). During the last five years more funding programs aimed to finance science-business cooperation for the R\&D commercialisation were established [29], [30]. Legal framework, especially addressing the public R\&D commercialisation issues, was improved allowing public scientific institutions more flexibility to commercialise their R\&D. However, the systemic public policy in Lithuania has weaknesses, which impede its effective application. There is clear misbalance between investments in "soft" and "hard" infrastructure, which is aimed at promoting and facilitating scientific knowledge and technology transfer. The development of the valleys is based on the development of the "hard" infrastructure - buildings and equipment. While "soft" infrastructure, such as network building, mentoring, business development and innovation support services, receive less investment. The available innovation support services are mainly consultation and trainings, which tend to lose their importance to the scientists and business which are looking for the opportunities to commercialise R\&D outputs. Owners of start-ups/spin-offs look for active business mentoring and early stage (pre-seed and seed) investments, which are still scarce in the Lithuanian innovation system. The available support and funding programs focus on quantitative results (such as number of patents, number of start-ups, number of projects), but rarely on qualitative outcomes, such as the impact to the general economic growth, the impact on the jobs creation and retention, the viability and commercial potential of technology commercialisation projects, etc. The science push approach is dominating even the funding programs aimed to promote commercialisation and business development: evaluation criteria for the $R \& D$ commercialisation projects emphasize scientific feasibility, but less attention if any is paid to the commercial potential and feasibility of such projects.

The number of public policy initiatives, addressing cultural problems, which influence technology transfer process, has been increasing during the last five years in Lithuania. These initiatives mainly are focused on the promotion of the entrepreneurial culture and the development of entrepreneurial skills, as well as on the promotion of science and technology to the general public. Increasing number of the initiatives is addressing academic entrepreneurship issues through the nonformal entrepreneurship education and training aimed at students and researchers. During such trainings, students and researchers simulate business development or start-up creation and/or create real knowledge and technology based start-ups. The aim of the entrepreneurship trainings is to develop necessary skills for R\&D outputs commercialisation, as well as encourage entrepreneurship in the academia. However, majority of the entrepreneurship promotion initiatives are financed through the EU Structural Funds and have to implement rigid and formal conditions. Usually entrepreneurship promotion projects have to result in creation of a priori defined number of start-ups, a priori defined number of training/consultation hours, etc. This situation does not allow risk taking, flexibility and failures, tolerance to which is an essential part of an entrepreneurial culture.

In conclusion, the EU public policy, addressing scientific knowledge and technology transfer challenges, incorporates policy means, based on all three approaches towards government involvement into the technology transfer process: market failure, system failure and cultural failure. However, despite comprehensive, flexible and evolutionary approach, which is advocated in the EU strategic documents, general indicators of the EU innovativeness are not satisfactory. The analysis of Lithuania's case shows that the EU recommendations are incorporated into the strategic level of the public policy, but there is a disconnect between the strategic goals and practical application of policy initiatives. The public policy mainly focuses on the allocation of government subsidies for 
the "hard" infrastructure and public R\&D financing programmes. Despite recent positive trends towards entrepreneurship and innovation support programs, there are still a lot of shortcomings.

\section{CONCLUSION AND RECOMMENDATIONS}

Based on the analysis of the theoretical rationale for the government intervention in knowledge and technology transfer processes and on the empirical analysis of the public policy documents and initiatives in the EU and Lithuania, it can be concluded that effective knowledge and technology transfer policy has to develop an ecosystem approach towards fostering technology transfer and innovation. Public policy on the EU and on national level of member states shall adopt more recommendations, based on the theoretical rationale of the system failure. Member states, such as Lithuania, have to develop more coherent, holistic public policy model with adequate incentives for the scientific knowledge and technology transfer.

The focus shall be shifted from quantity towards quality of the policy results. The importance of technology transfer and commercialisation to the economic development has to be acknowledged not only on the strategic level, but on the operational level of public policy as well. Such acknowledgement can lead to the development of qualitative models for the evaluation of $\mathrm{R} \& \mathrm{D}$ projects and other initiatives, submitted for public financing. The focus towards quality is also necessary in the results of the projects and initiatives, since quantitative results are not enough to prove the success or the impact of the projects. For example, the quantitative result - number of start-ups created during or after the entrepreneurship training project - can be complemented by the qualitative results - the revenue start-ups generated, the private investments start-ups attracted, the jobs start-ups created and/or retained during certain number of years.

The focus has to be shifted from subsidising towards commercialisation of the R\&D outputs and the market pull approach has to be promoted as opposed to the science push approach. It is not enough to address the scientific knowledge and technology supply problems. More R\&D projects without focus on commercialisation do not lead to more innovative outcomes, such as new products and services. It is recommended to include commercialisation of the $R \& D$ outputs into all science-business cooperation projects, fully or partially funded by the government. Science-business cooperation has to be purposeful, i.e., focused on the commercial application of the R\&D outputs. Public R\&D funding shall adopt a researcher-centric approach and allocate funds based not on the institutional affiliation but on the competence of researchers and the quality of the research project.

Soft infrastructure and its diversification have to be the priority when developing the infrastructure for a sciencebusiness cooperation and scientific knowledge and technology transfer and commercialisation. Soft infrastructure shall focus on network building, active technology transfer and mentoring services for the researchers and entrepreneurs, development and support to the risk capital infrastructure, offering pre-seed and seed investment or grants. Scientific institutions have to be encouraged to review their technology transfer policy and develop incentives for the researchers to commercialise their R\&D outputs.

The proposed ecosystem approach can be adopted with the aim to create comprehensive and holistic public policy in the field. Ecosystem approach means that every step in the knowledge and technology transfer process is addressed through the respective public policy means and all public policy initiatives lead to the main goal - commercialisation of R\&D.

\section{REFERENCES}

[1] Rogers, E. M., Takegami, S., Yin, J., "Lessons Learned About Technology Transfer," in Systems and Policies for the Global Learning Economy. Edited by David V. Gibson, Chandler Stolp, Pedro Conceição, and Manuel V. Heitor, International Series on Technology Policy and Innovation, Praeger: Westport (Connecticut), London, 2003, pp. 369-382.

[2] Gustafsson, R., Autio F., "Grounding for innovation policy: the market, system and social-cognitive failure rationales," in The Future of Science, Technology and Innovation Policy: Linking Research and Practice, Conference papers, University of Sussex, Sep. 11-13, 2006.

[3] Rasmussen, E., Moen, Ø. Gulbrandsen, M., "Initiatives to promote commercialization of university knowledge," in Technovation, vol. 26, 2006, pp. 518-533.

[4] Breschi. St., "Spatial patterns of innovation: evidence from patent data," in The Organization of Economic Innovation in Europe. Edited by Alfonso Gambardella and Franco Malerba, Cambridge University Press, 1999, pp. 71-102.

[5] Fiedler, H., "Technology Transfer - A Tool to Promote Innovation and Cooperation between Science and Industry," in Utilizing Technology Transfer to Develop Small and Medium Enterprises. Edited by Eugenia Bulumac and Richard A. Bendis. IOS Press, 2001, p. 119-128.

[6] Berkhout, A. J., Hartmann, D., Van Der Duin, P., Ortt, R., "Innovating the innovation process," in International Journal of Technology Management, vol. 34, no. 3/4, 2006, pp. 390-404. http://dx.doi.org/10.1504/IJTM.2006.009466

[7] European Commission. Innovation Union Scoreboard 2013. European Union, 2013.

[8] Leydesdorff, L., Etzkowitz, H., "A Triple Helix of University-IndustryGovernment Relations," in Universities and the Global Knowledge Economy: A Triple Helix of University-Industry-Government Relations. Edited by Henry Etzkowitz and Loet Leydesdorff. Printer: London, Washington, 1997, pp. 155-162.

[9] Sharif, N., "Emergence and development of the National Innovation Systems concept," in Research Policy, vol. 35, no. 5, June 2006, pp. 745-766. http://dx.doi.org/10.1016/j.respol.2006.04.001

[10] Etzkowitz, H., Webster, A., "Entrepreneurial Science: The Second Academic Revolution," in Capitalizing Knowledge: New Intersections of Industry and Academia. Edited by Henry Etzkowitz, Andrew Webster, and Peter Healey. State University of New York Press, 1998, pp. 21-46.

[11] Bozeman, B., "Technology transfer and public policy: a review of research and theory," in Research Policy, vol. 29, no. 4-5, Apr. 2000, pp. 627-655. http://dx.doi.org/10.1016/S0048-7333(99)00093-1

[12] Hauknes, J., Norgren, L., Economic rationales of government involvement in innovation and the supply of innovation-related services. The STEP Report Series. Stiftelsen STEP, 1999.

[13] Stephen, M., Scott, J. T., "The nature of innovation market failure and the design of public support for private innovation," in Research Policy, vol. 29, no. 4-5, Apr. 2000, pp. 437-447.

[14] Malerba, F., "Public Policy and Industrial Dynamics: An Evolutionary Perspective," Targeted Socio-Economic Research (TSER) program of the European Commission (DGXII) under the Fourth Framework Program, System of Innovation Research Program, Sub-Project 3.1.1.: System Theories of Innovation: Policy Implication, Linköping University (Sweden), 1998.

[15] Scotchmer, S., "Innovation and Incentives," The MIT Press: Cambridge, Massachusetts, London (England), 2004 
[16] European Commission, "Giving More for Research in Europe: The role of foundations and the non-profit sector in boosting R\&D investment," Report by an Expert Group on Measures and actions to promote the role of foundations and the non-profit sector in boosting $R \& D$ investment, September 2005.

[17] Ebner, A., "The Institutional Analysis of Entrepreneurship: Historist Aspects of Schumpeters Development Theory," in Joseph Alois Schumpeter: Entrepreneurship, Style and Vision. Edited by Jurgen G. Backhaus. Secaucus, NJ, USA: Kluwer Academic Publishers, 2003, pp. $117-139$.

[18] Ahmad. N., Hoffmann. A. N., "A Framework for Addressing and Measuring Entrepreneurship". OECD Statistics Working Paper, STD/DOC (2008) 2, Jan. 2008.

[19] Putnam, R. D., "Foreword," in Role of Social Capital in Development: An Empirical Assessment. Edited by Christiaan Grootaert and Thierry van Bastelaer. New York: Cambridge University Press, 2002, pp. xxi-xxii.

[20] European Commission, "Europe 2020" [Online]. Available: http://ec.europa.eu/europe2020/index_en.htm. [Accessed: Oct. 1, 2013].

[21] European Commission, "Innovation Union. A Europe 2020 Initiative," [Online]. Available: http://ec.europa.eu/research/innovationunion/index_en.cfm. [Accessed: Oct. 1, 2013].

[22] European Commission. "Other studies and research on innovation". [Online]. Available: http://ec.europa.eu/research/innovationunion/index_en.cfm?pg=other-studies. [Accessed: Oct. 1, 2013].

[23] European Commission, "Improving knowledge transfer between research institutions and industry across Europe: embracing open innovation," Voluntary guidelines for universities and other research institutions to improve their links with industry across Europe. $\operatorname{COM}(2007) 182$ final. Brussels, 4.4.2007.

[24] European Council, "The conclusions of the European Council," (Feb. 4, 2011). EUCO 2/1/11, REV 1. Brussels, Mar. 8, 2011.

[25] European Commission, Giving in evidence, "Fundraising from philanthropy in European universities," Luxembourg: Publications Office of the European Union, 2011.
[26] European Commission, "EUROSTAT," Science, technology and innovation statistics, [Online]. Available: http://epp.eurostat.ec.europa.eu/ portal/page/portal/science_technology_innovation/data/main_tables. [Accessed: Oct. 2, 2013].

[27] Ministry of Education and Science of the Republic of Lithuania, "Integrated Science, Studies and Business centres," (Valleys), [Online]. Available: http://www.smm.lt/web/en/science1/science_1. [Accessed: Oct. 1, 2013].

[28] "Business Angels Fund I," [Online]. Available: http://www.mesinvest.lt/ index.php/business-angels-fund-i/82. [Accessed: Oct. 1, 2013].

[29] Ministry of Education and Science of the Republic of Lithuania, "Commercialization of R\&D results," (orig. MTEP rezultaty komercinimas). [Online]. Available: http://www.smm.lt/web/lt/mokslas/ mokslo_ir_verslo_bendradarbiavimas/mtep_rezult. [Accessed: Oct. 2, 2013].

[30] "Agency for Science, Innovation and Technology," [Online]. Available: http://www.mita.lt/en/istaigos-informacija/about-mita/. [Accessed: Oct. 2, 2013].

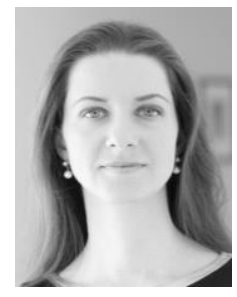

Auste Kiskiene received the Doctoral degree in Management and Administration from Mykolas Romeris University (Lithuania) in 2010. She received the Master's degree in Political Sciences from the Vilnius University (Lithuania) in 2004

Dr. Kiskiene is an Associate Professor and ViceRector with Kazimieras Simonavicius University (Vilnius, Lithuania) and a Visiting Professor with Tongji University (Shanghai, P.R. China). Previously Dr. Kiskiene was Associate Professor with Vilnius Gediminas Technical University and Mykolas Romeris University and Head of Technology Transfer Centre with Sunrise Valley Science and Technology Park. Her research interests include technology transfer policy, R\&D commercialisation, innovation and technology management, technological entrepreneurship, knowledge economy.

Address: Kazimieras Simonavicius University, J. Basanaviciaus Str. 29A, Vilnius, Lithuania.

E-mail: auste.kiskiene@ksu.lt 